REVIEW

\title{
The role of hypoxia inducible factor 1 (HIF-1) in hypoxia induced apoptosis
}

\author{
A E Greijer, E van der Wall
}

J Clin Pathol 2004;57:1009-1014. doi: 10.1136/jcp.2003.015032

Apoptosis can be induced in response to hypoxia. The severity of hypoxia determines whether cells become apoptotic or adapt to hypoxia and survive. A hypoxic environment devoid of nutrients prevents the cell undergoing energy dependent apoptosis and cells become necrotic. Apoptosis regulatory proteins are delicately balanced. In solid tumours, hypoxia is a common phenomenon. Cells adapt to this environmental stress, so that after repeated periods of hypoxia, selection for resistance to hypoxia induced apoptosis occurs. These resistant tumours probably have a more aggressive phenotype and may have decreased responsiveness to treatment. The key regulator of this process, hypoxia inducible factor 1 (HIF-1), can initiate apoptosis by inducing high concentrations of proapoptotic proteins, such as BNIP3, and can cause stabilisation of p53. However, during hypoxia, antiapoptotic proteins, such as IAP-2, can be induced, whereas the proapoptotic protein Bax can be downregulated. During hypoxia, an intricate balance exists between factors that induce or counteract apoptosis, or even stimulate proliferation. Understanding the regulation of apoptosis during hypoxia and the mechanisms of resistance to apoptosis might lead to more specific treatments for solid tumours.

See end of article for authors' affiliations

Correspondence to: Dr A E Greijer, Departments of Pathology and Medical Oncology VU University Medical Centre, Amsterdam, 108 HV, The Netherlands; ae. greijer@vumc.nl

Accepted for publication 26 January 2004
M ammalian cells have developed a range of adaptations to survive acute and even prolonged hypoxia. Hypoxia reduces the ability of a cell to maintain its energy level, because less ATP will be obtained from glycolysis than from oxidative phosphorylation. Cells will adapt by activating the expression of genes involved in metabolic adaptation, such as those involved in glycolysis. In addition, cell proliferation and angiogenesis will be stimulated, enabling better oxygenation of the tissue. ${ }^{1}$ Severe hypoxia causes a high mutation rate, resulting in point mutations, which may be explained by reduced DNA mismatch repair activity resulting from decreased MLH1 and PMS2 concentrations, which are caused by hypoxia. ${ }^{2}$ In addition, hypoxia induces genetic instability by the induction of fragile sites causing gene amplification. ${ }^{3-5}$ Therefore, during severe hypoxia or anoxia, the cell initiates a cascade of events that leads to apoptotic cell death, thereby preventing the accumulation of cells with hypoxia induced mutations. ${ }^{6}$
Hypoxia is a common phenomenon in solid tumours because impaired vascular function results in an inadequate blood supply. The supply of oxygen and nutrients is severely hampered by the malformed vessels. The combination of a lack of oxygen and a lack of nutrients causes energy deprivation. Low ATP concentrations in hypoxic tumour cells disable the apoptotic cascade and induce cell death by necrosis. ${ }^{7}$ Severe hypoxia in the presence of energy stimulates cells to undergo apoptosis, whereas oxygen levels above $0.5 \%$ prevent cell death. ${ }^{8}$ Therefore, tight regulation of cellular responses to the microenvironment is needed.

\begin{abstract}
"During severe hypoxia or anoxia, the cell initiates a cascade of events that leads to apoptotic cell death, thereby preventing the accumulation of cells with hypoxia induced mutations"
\end{abstract}

Cells in rapidly growing tumours are intermittently, or sometimes constantly, exposed to hypoxic conditions. In severe or prolonged hypoxia, cells will initiate the process of programmed cell death. Some cells may adapt to the environmental stress, escape necrosis and apoptosis, and survive. These selected hypoxia resistant cells probably have a more aggressive phenotype. ${ }^{10}$ Such tumour cells with a reduced sensitivity to apoptosis will be less responsive to anticancer treatment. ${ }^{11}$

The key regulator of the hypoxia response is the hypoxia inducible factor 1 (HIF-1). HIF-1 has a complex role. HIF-1 can induce apoptosis, ${ }^{12}{ }^{13}$ prevent cell death, or even stimulate cell proliferation. ${ }^{14}$ This review will focus on the delicate balance between the adaptation of the cell to the hypoxic environment and self sacrifice of the cell by apoptosis, by which the accumulation of mutated cells is prevented.

\section{HYPOXIA INDUCIBLE FACTOR 1}

HIF-1 is involved in embryonic development, ${ }^{15-17}$ tumour growth, metastasis, ${ }^{18}{ }^{19}$ and apoptosis. ${ }^{12} 20$

Abbreviations: Apaf-1, apoptotic protease activating factor-1; BNIP3, BCL-2/adenovirus E1B 19 kDa interacting protein 3; ES, embryonic stem; HIF-1, hypoxia inducible factor 1; HRE, hypoxia response element; IAP-2, inhibitor of apoptosis protein 2; IRES, internal ribosome entry site; Jabl, jun activation domain binding protein 1; JNK, c-Jun $\mathrm{NH}_{2}$ terminal kinase; $\mathrm{NF}-\kappa \mathrm{B}$, nuclear factor $\kappa \mathrm{B}$; ODD, oxygen dependent degradation; $\mathrm{PI} 3 \mathrm{~K}$, phosphoinositide-3 kinase; ROS, reactive oxygen species; SAPK, stress activated protein kinase; VHL, von Hippel Lindau 
HIF- 1 is a heterodimer composed of the rate limiting factor HIF $1 \alpha$ and the constitutively expressed HIF- $1 \beta \cdot{ }^{21}$ HIF- $1 \beta$ is also called the aryl hydrocarbon receptor nuclear translocator. It heterodimerises with several other factors, such as the Ahr transcription factor. ${ }^{22}$ HIF- $1 \alpha$ is induced by hypoxia, and also by oncogenes, such as HER-2/neu, v-src, and ras, as reviewed by Semenza. ${ }^{23}$ The induction of HIF-1 by hypoxia takes place at the protein level, because HIF-l $\alpha$ mRNA expression remains unchanged. During normoxia, HIF- $1 \alpha$ protein is expressed but is unstable. Rapid degradation of HIF-1 by the proteasome results from its ubiquitination by the product of the Von Hippel Lindau tumour suppressor gene (VHL). In patients with loss of the VHL gene, HIF- $1 \alpha$ and HIF- 1 dependent genes, such as angiogenesis factors, are also expressed during normoxia. ${ }^{24}$ Vascular tumours are often seen in these patients, who suffer from the von Hippel Lindau syndrome. The binding of HIF- $1 \alpha$ to pVHL requires a modification of HIF- $1 \alpha$ by proline hydroxylases in the oxygen dependent degradation domain (ODD) within the HIF-l $\alpha$ protein. ${ }^{25-27}$ These enzymes are oxygen dependent and therefore HIF- $1 \alpha$ cannot be hydroxylated during hypoxia. In those circumstances, HIF- $1 \alpha$ accumulates and is translocated to the nucleus. Here it binds to HIF-1 $\beta$ to form the active transcription factor HIF-1.

Stabilisation of HIF-l $\alpha$ by the ODD domain is not only caused by prolyl hydroxylases. HIF- $1 \alpha$ becomes unstable when bound to p53. ${ }^{28} \mathrm{Jabl}$ (jun activation domain binding protein 1) directly interferes with the HIF- $1 \alpha$-p53 complex and leads to stabilisation of the HIF- $1 \alpha$ protein during hypoxia. ${ }^{29}$

In addition to it regulation by stabilisation, HIF- $1 \alpha$ is also regulated at the translational level. Recently, internal ribosome entry site (IRES) sequences were detected in the promoters of various hypoxia inducible genes, such as VEGF and HIF- $1 .^{30}{ }^{31}$ During hypoxia, the translation of classic cap dependent mRNA transcription is reduced, and only mRNA containing an IRES sequence will be translated. To become active, HIF-l $\alpha$ complexes with HIF-1 $\beta$. The HIF-1 complex can bind to hypoxia response element (HRE; 5'-RCGTG-3') sequences in the promoter of HIF-l target genes to initiate gene expression. ${ }^{32}$ Many genes regulated by HIF-l $\alpha$ are involved in several adaptive pathways including metabolism, angiogenesis, and survival to overcome hypoxic stress. ${ }^{1}$ However, in the presence of different environmental factors HIF-l is involved in apoptosis. ${ }^{33}$

\section{APOPTOSIS}

Cells encountering environmental stress can undergo apoptosis. The characteristics of apoptosis are chromatin condensation, membrane blebbing, phosphatidylserine exposure on the cell surface, cytoplasmic shrinkage, the formation of apoptotic bodies, and DNA fragmentation. ${ }^{34}$ Apoptosis is an energy dependent process, in contrast to necrosis, which also occurs in the absence of ATP. ${ }^{35}$ Apoptosis is regulated by a cascade of proteins called caspases. Caspases are the apoptosis executor proteins and are present as pro-forms in all cells. After cleavage, caspases become active and initiate pathways leading to apoptosis.

The signalling pathway leading to programmed cell death is fine tuned by positive and negative regulators, and a tight balance between these factors decides whether the cell undergoes apoptosis or survives. Proteins that can shift the balance towards survival are the antiapoptotic proteins $\mathrm{Bcl}-2$ and Bcl-xL, whereas the proapoptotic proteins Bax, Bad, Bak, and Bid induce programmed cell death. ${ }^{36}$

\footnotetext{
"Apoptosis is regulated by a cascade of proteins called caspases"
}

An important regulator of apoptosis after DNA damage is the p53 protein. After DNA damage, p53 can induce the Bax and Bak proteins, which regulate the release of cytochrome $\mathrm{C}$ from the mitochondria, thereby initiating the cascade leading to apoptosis. ${ }^{37}$

After the induction of apoptosis by hypoxia, cytochrome $\mathrm{C}$ is released into the cytoplasm (fig 1 ). Cytochrome $\mathrm{C}$ binds to the apoptotic protease activating factor 1 (Apaf- 1$).^{38}$ Apaf- 1 activates caspase 9, which in turn cleaves caspases 3 and $6,^{38}{ }^{39}$ leading to cell death.

In addition to intrinsic apoptotic pathways, extrinsic pathways have been identified that can initiate and execute the cell death process. Apoptosis by extrinsic pathways is initiated by death ligands, such as the Fas ligand or tumour necrosis factor $\alpha^{40}$ leading finally to the activation of caspase 8 and caspase $3 .^{41}$

\section{HYPOXIA AND APOPTOSIS}

Hypoxia can induce apoptosis by causing hyperpermeability of the inner mitochondrial membrane, which leads to the release of cytochrome $\mathrm{C}$ (fig 1 ). The most direct induction of hypoxia induced apoptosis is the inhibition of the electron transport chain at the inner membrane of the mitochondria (fig 1). The lack of oxygen inhibits the transport of protons and thereby causes a decrease in the membrane potential. The reduction of mitochondrial derived ATP causes activation of Bax or Bak, leading to cytochrome $\mathrm{C}$ release into the cytosol. ${ }^{7}$ Hence, fibroblasts of mice lacking Bax and Bak genes are resistant to oxygen deprivation induced apoptosis. ${ }^{35}$ In addition to energy deprivation, radical formation, in particular reactive oxygen species (ROS) generation, contributes to hypoxia induced apoptosis. It has been reported that the activation cascade resulting from ROS in human neuroblastoma cells is different from classic mitochondrial mediated apoptosis. In this case, the initiator caspase 9 is cleaved directly to the active form by caspases 3 and 12, without the involvement of cytochrome $\mathrm{C}$ in response to hypoxia. ${ }^{42}$ It is only after cleavage of caspase 9 that mitochondrial permeability is increased, which then results in the activation of Apaf- $1 .{ }^{43}$

A third mechanism by which hypoxia can induce apoptosis is the activation of c-Jun $\mathrm{NH}_{2}$-terminal kinase ( $\mathrm{JNK}$ ), also termed stress activated protein kinase (SAPK). This mechanism has been reported in melanoma cells. JNK/SAPK is involved in the process of apoptosis, ${ }^{44}$ because dominant negative mutants of JNK/SAPK inhibited hypoxia induced apoptosis. Wild-type JNK/SAPK had a slight proapoptotic effect. Inhibiting JNK/SAPK at normoxia had no effect on apoptosis. $^{45}$

In contrast to the proapoptotic effects of hypoxia, cells can become resistant to apoptosis during hypoxia. Dong et al showed that cells treated with a strong apoptosis inducer, staurosporine, were less sensitive to apoptosis in severe hypoxia (near $0 \%$ oxygen) than when oxygen levels are normal. ${ }^{46}$ Death resistance of hypoxic cells takes place on at least two levels: in the mitochondria and in the cytosol. In staurosporine treated cells, translocation of the proapoptotic protein Bax to the mitochondria was suppressed during hypoxia. Accumulation of Bax in the mitochondria caused the release of cytochrome $\mathrm{C}$ into the cytosol, which was strongly reduced in the hypoxic environment. This prohibited the cascade leading to cell death. Bax translocation was suppressed as a result of increased concentrations of the inhibitor of apoptosis protein 2 (IAP-2). Resistance to apoptosis was strongly abolished by decreased availability of IAP-2 caused by immunodepletion. IAP-2, together with the factors that prevent Bak translocation and preserve mitochondrial integrity, may facilitate cell survival during hypoxia. ${ }^{46}$ Increased IAP-2 expression is induced by the 


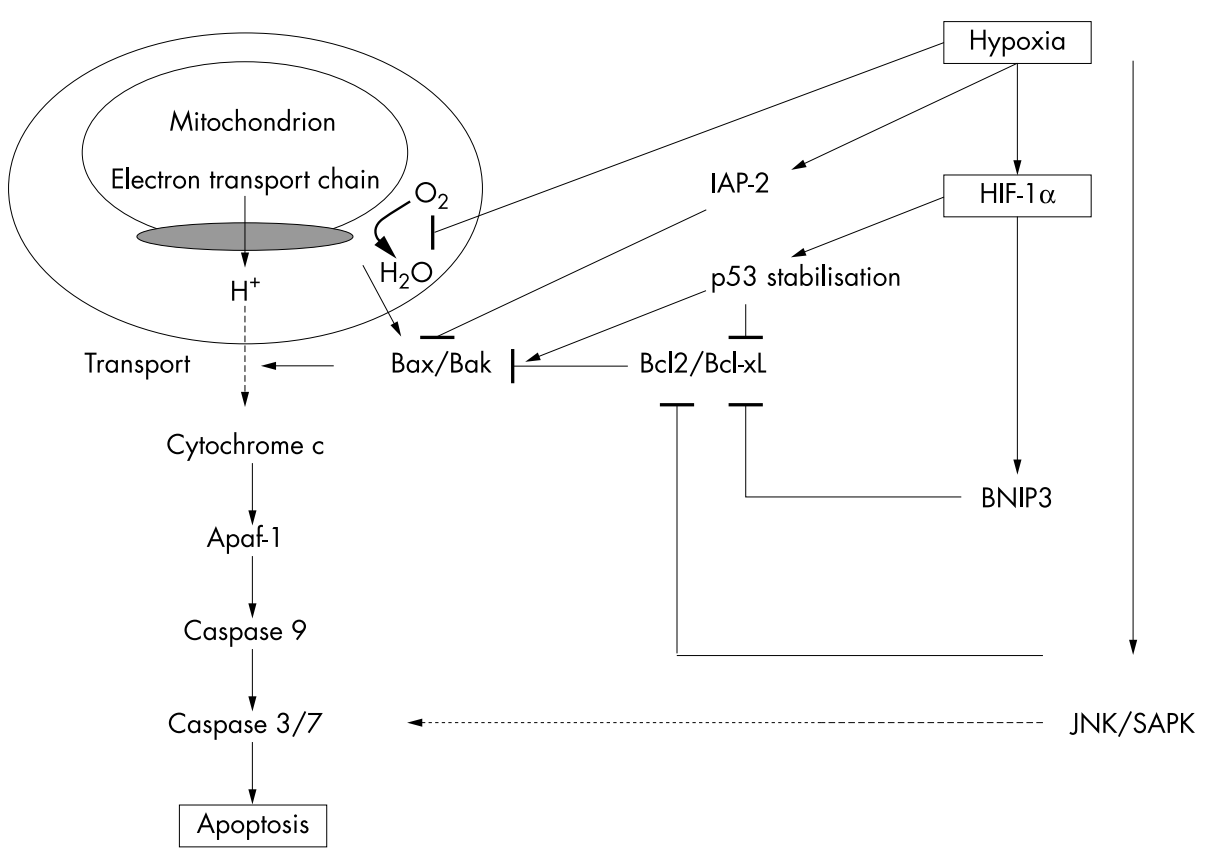

Figure 1 Schematic representation of signalling pathways induced by hypoxia leading to apoptosis. The involvement of HIF- $1 \alpha$ is depicted in these pathways. The solid lines indicate a direct interaction, the dashed line an indirect interaction. Apaf-1, apoptotic protease activating factor-1; BNIP3, $\mathrm{BCL}-2$ /adenovirus E1B $19 \mathrm{kDa}$ interacting protein 3 ; HIF-1, hypoxia inducible factor $1 ;$ IAP-2, inhibitor of apoptosis protein 2; JNK, c-Jun $\mathrm{NH}_{2}$ terminal kinase; SAPK, stress activated protein kinase.

hypoxia induced transcription factor nuclear factor $\kappa \mathrm{B}$ (NF$\kappa \mathrm{B})$, and its induction is independent of HIF-1. ${ }^{47}$ An alternative mechanism for increased IAP-2 synthesis may be the activation of IRES, which are present in the promoter of XIAP, another IAP gene. ${ }^{48}$ As described above for HIF-1, the IRES may be responsible for increased translation of XIAP mRNA during hypoxia, thereby preventing the cell from undergoing apoptosis. ${ }^{31}$

In addition, VHL has been shown to have a protective role in chemical induced apoptosis in renal cells. Cells lacking VHL are sensitive to apoptosis, but reintroduction of VHL rendered the cells resistant to apoptosis. Prevention of apoptosis by VHL may act via Bcl-2 dependent pathways, because downregulation of $\mathrm{Bcl}-2$ expression by antisense oligonucleotides in VHL positive cells made them sensitive to apoptosis. $^{49}$

\section{"Death resistance of hypoxic cells takes place on at least} two levels: in the mitochondria and in the cytosol"

Both severe hypoxia and the presence of ATP are required to induce apoptosis. Oxygen levels above $0.5 \%$ prevent cells from undergoing apoptosis. ${ }^{9}$ Cell survival under mild hypoxia is mediated by phosphoinositide-3 kinase (PI3K) and its downstream target Akt. ${ }^{50}$ The PI3K/Akt signalling pathway is important for cell survival and proliferation because it prevents Bad from inhibiting the antiapoptotic activity of Bcl-xL. Akt induces NF- $\kappa B$, which leads to cell survival. ${ }^{50}$ The importance of the PI3K/Akt pathway is emphasised by the fact that tumours that overexpress HER-2/neu, thereby activating the PI3K/Akt pathway, become resistant to apoptosis. Resistance to apoptosis is mediated by the PI3K/ Akt pathway and can be reversed by inhibitors such as LY294002 and wortmannin. ${ }^{51}$

\section{HIF- 1 AND APOPTOSIS}

HIF- $1 \alpha$ is involved in hypoxia induced apoptosis. Hypoxia in combination with hypoglycaemia reduces proliferation and increases apoptosis in wild-type embryonic stem (ES) cells, but not in ES cells with inactivated HIF- $1 \alpha$ genes. The reduced rate of hypoxia induced apoptosis may explain why tumours from HIF- $1 \alpha$ knockout ES cells grow faster than wild-type cells. ${ }^{12}$ Two homologues of HIF- $1 \alpha$ are knownHIF- $2 \alpha$ and HIF- $3 \alpha$ - and it was thought that HIF- $2 \alpha$ or HIF$3 \alpha$ might substitute the function of HIF-l $\alpha$ in cells lacking HIF- $1 \alpha$. However, HIF- $2 \alpha$ deficiency does not protect cells from hypoxia induced apoptosis as HIF- $1 \alpha$ does. ${ }^{52}$ Whether HIF- $3 \alpha$ induces apoptosis has not yet been studied.

HIF- $1 \alpha$ can induce apoptosis via two mechanisms. First, it can increase the stability of the product of the tumour suppressor gene p53. In environmental stress or DNA damage, p53 induces programmed cell death by regulating proteins such as Bax, or it can cause growth arrest, which is mediated by $\mathrm{p} 2 \mathrm{l}$. Recently, it was shown that HIF- $1 \alpha$ directly binds to the p53 ubiquitin ligase mdm2 both in vivo and in vitro, thereby stabilising p53. ${ }^{53}$ However, another report showed a direct binding of p53 to the ODD domain of HIF$1 \alpha .^{54}$ HIF- $1 \alpha$ interacts with wild-type p53 but not with tumour derived mutant $\mathrm{p} 53 .{ }^{55}$ This may reflect a difference in behaviour of HIF-l $\alpha$ in physiological circumstances compared with a tumour environment.

Second, in hypoxic perinecrotic regions of tumours, the proapoptotic proteins BNIP3 (BCL2/adenovirus E1B $19 \mathrm{kDa}$ interacting protein 3) and NIX, a BNIP3 homologue, are overexpressed at the transcriptional level. ${ }^{56}$ BNIP3 is upregulated by hypoxia in human carcinoma cell lines, endothelial cells, and macrophages. Overexpression of BNIP3 in Rat-1 fibroblasts and breast cancer cells (MCF7) induces apoptosis by binding to and inhibiting the antiapoptotic proteins Bcl-2 and Bcl-xL. ${ }^{57}$ Hypoxia induced apoptosis mediated by BNIP3 may be HIF- $1 \alpha$ dependent because cells lacking HIF- 1 cannot produce large amounts of BNIP3 and a reduced cell death rate is seen. ${ }^{58}$ The BNIP3 promoter contains an HRE so that HIF-1 can induce the expression of this gene..9 Apart from initiating apoptosis, BNIP3 may also be involved in inducing necrosis. The disruption of the mitochondria by BNIP3 is different from the action of other proapoptotic proteins: the cell death induced by BNIP3 resembles necrosis in fibroblasts. ${ }^{60}$ BNIP3 may prove to be an important protein for the elimination of damaged cells by undergoing rapid cell death.

HIF- $1 \alpha$ does not only induce, but may also prevent, apoptosis. In pancreatic cancer cell lines, high concentrations of HIF- $1 \alpha$ were seen at normoxia, and these may have been caused by activation of the PI3K/Akt pathway, rather than 
hypoxia. These cells showed more resistance to apoptosis caused by hypoxia and glucose deprivation than did cell lines with low HIF- $1 \alpha$ expression at normoxia. ${ }^{14}$ The reduced sensitivity to apoptosis was seen in acute hypoxia; the influence of chronic hypoxia was not studied. In addition, Chen et al recently reported that dominant negative HIF- $1 \alpha$ rendered pancreatic cancer cells sensitive to apoptosis and growth inhibition by hypoxia and glucose deprivation. ${ }^{61}$

It can be concluded that HIF-1 plays a role in hypoxia induced apoptosis, but that the exact mechanism by which it acts is not yet clear. The effect of HIF-1 might be influenced by other factors, which may determine whether HIF-1 shifts the balance towards apoptosis or acts as an antiapoptotic factor. ${ }^{62}$

\section{HYPOXIA, HIF-1, AND APOPTOSIS IN TUMOURS}

Hypoxia is commonly found in solid tumours of various origins. Selection by hypoxia renders tumour cells resistant to hypoxia induced apoptosis. ${ }^{63}$ These cells with a reduced apoptotic potential may also explain the resistance of many solid tumours to cancer treatment. ${ }^{11}$

In carcinomas of the uterine cervix, proliferation and the state of hypoxia appeared to be two independent predictors of outcome. ${ }^{64}$ In the hypoxic cell compartment, cells are in growth arrest. However, small numbers of proliferating cells could be seen. ${ }^{65}{ }^{66}$ In one study, an increased overlap was seen between hypoxia and proliferating cells after radiotherapy in canine tumours. ${ }^{67}$ In human soft tissue sarcomas, hypoxic tumours contained the fastest proliferating tumour cells. ${ }^{68}$ The use of immunohistochemistry to investigate proliferation patterns and hypoxic profiles may identify clinically relevant cell populations in solid tumours with a more aggressive phenotype. ${ }^{69}$

The prognostic impact of hypoxia related apoptosis is not yet clear. The prognostic value may differ between various histological tumour types from different organs. For example, in squamous cell carcinomas of the uterine cervix, a high apoptotic index indicated poor prognosis, ${ }^{70} 71$ whereas in cervical adenocarcinomas a high apoptotic index after treatment indicated a good prognosis. ${ }^{72}{ }^{73}$ One problem might be the difficult distinction between spontaneous apoptosis (a common phenomenon in tumours) and treatment induced apoptosis.

HIF- $1 \alpha$ is involved in cell proliferation and apoptosis, and HIF- $1 \alpha$ overexpression, as detected by immunohistochemistry, is often found in different solid tumours. ${ }^{74}{ }^{75}$ In lymph node negative patients with breast cancer, HIF- $1 \alpha$ overexpression appeared to be a negative prognostic factor and correlated with increased proliferation as measured by Ki$67 .{ }^{74}{ }^{76}$ In oral squamous cell cancer, HIF- $1 \alpha$ overexpression correlated with a low apoptotic index, ${ }^{77}$ but in invasive breast cancer, the opposite correlation was described. ${ }^{78}$ No relation between the proliferation of lung tumours and HIF-1 ( $\alpha$ and $\beta$ ) was seen when the expression of cyclin A and the phases of the cell cycle were analysed in relation to the presence of HIF-l $\alpha$. However, a correlation was seen between HIF- 1 expression and the apoptotic index. ${ }^{79}$ This correlation between HIF- $1 \alpha$ expression and apoptosis was also seen in patients with non-small cell lung carcinomas, studying the proapoptotic factors caspase 3, Fas, and the Fas ligand. ${ }^{80}$

\footnotetext{
"Because hypoxia inducible factor 1 (HIF-1) is related to resistance to chemotherapy and radiotherapy, targeting HIF-1 may help improve antitumour treatment"
}

The relation between the antiapoptotic protein Bcl-2 and the overexpression of HIF- 1 is controversial. In non-small cell lung cancer, HIF-1 expression showed a significant inverse
Take home messages

- Severe and prolonged hypoxia may initiate apoptosis, whereas cells often adapt to acute and mild hypoxia and survive

- The key regulator of hypoxia induced apoptosis is hypoxia inducible factor 1 (HIF-1), which acts in combination with many other factors, and can either induce or inhibit apoptosis

- HIF-1 can initiate hypoxia mediated apoptosis by increasing the expression of $\mathrm{Bcl}-2$ binding proteins (BNIP3 and NIX), thereby inhibiting the antiapoptotic effect of Bcl-2, or by stabilising wild-type p53-if the cell already has a p53 gene mutation, hypoxia induced apoptosis is prevented

- Hypoxia by itself can also prevent apoptosis by inducing the expression of the antiapoptotic protein IAP-2

- HIF-1 may also have an antiapoptotic function because cells with high amounts of HIF-1 are more resistant to hypoxia induced apoptosis

- Further investigations into the function of HIF-1 in the regulation of apoptosis by hypoxia are required because understanding the regulation of apoptosis during hypoxia and the mechanisms of resistance to apoptosis might lead to more specific treatments for solid tumours

association with Bcl-2 expression. $.^{81} \mathrm{Bcl}-2$ overexpressing lung carcinomas have a relatively good survival ${ }^{82}$; however, in a breast carcinoma study the opposite was observed-HIF-1 and $\mathrm{Bcl}-2$ had a strong positive correlation. ${ }^{78}$ The differences may be explained by tissue specific regulation of hypoxia induced apoptosis. A more aggressive clinical behaviour was seen in tumours overexpressing HIF- $1 \alpha$, and this may be related to resistance to apoptosis. Because HIF-1 is related to resistance to chemotherapy and radiotherapy, ${ }^{83}{ }^{84}$ targeting HIF-1 may help improve antitumour treatment. In this case, the inhibition of HIF-1 may not be sufficient as a treatment, but targeting HIF-1 may decrease resistance to the conventional treatment.

\section{CONCLUSION}

Severe and prolonged hypoxia may initiate apoptosis, whereas under acute and mild hypoxia cells may adapt to this environmental stress and will survive. Fine tuning of the regulation of apoptosis by hypoxia is influenced by HIF-1 in combination with many other factors. The role that the key regulator of hypoxia, HIF-1, plays in this hypoxia mediated programmed cell death is not entirely clear yet. HIF-1 can initiate hypoxia mediated apoptosis by increasing the expression of Bcl-2 binding proteins-BNIP3 and NIXthereby inhibiting the antiapoptotic effect of Bcl-2. A different mechanism of inducing apoptosis is by stabilisation of wild-type p53 by HIF-1. If the cell already has a p53 gene mutation, hypoxia induced apoptosis is prevented. However, hypoxia by itself can also prevent apoptosis by inducing the expression of the antiapoptotic protein IAP-2. HIF-1 may also have an antiapoptotic function because cells with high amounts of HIF-l are more resistant to hypoxia induced apoptosis.

Although many studies have focused on the role of HIF-1 in angiogenesis, it is clear that the function of HIF-1 in the regulation of apoptosis by hypoxia deserves more attention. 
Translating the in vitro data to the clinic is still rather complex because of the dual role of HIF-1. In addition, different cell types may influence the balance of apoptosis. A better understanding of the regulation of apoptosis by hypoxia in solid tumours may enhance insight into tumour behaviour and the effect of hypoxia on antitumour treatments.

\section{ACKNOWLEDGEMENTS}

We thank Professor PJ van Diest, Dr A Shvarts, Professor VW van Hinsbergh, and Dr GA Meijer for helpful discussions and critical reading of the manuscript. Part of this work was financially supported by the first AEGON International Scholarship in Oncology (AEG)

\section{Authors' affiliations}

A E Greijer, Departments of Pathology and Medical Oncology, VU University Medical Centre, Amsterdam, 1081 HV, The Netherlands E van der Wall, Departments of Pathology and Medical Oncology, UMCU, Utrecht, 3508 GA, The Netherlands

\section{REFERENCES}

1 Semenza GL. Targeting HIF-1 for cancer therapy. Nat Rev Cancer 2003;3:721-32

2 Perou CM, Sorlie T, Eisen MB et al. Molecular portraits of human breast tumours. Nature 2000:406:747-52.

3 Rice GC, Hoy C, Schimke RT. Transient hypoxia enhances the frequency of dihydrofolate reductase gene amplification in Chinese hamster ovary cells. Proc Natl Acad Sci U S A 1986:83:5978-82.

4 Young SD, Marshall RS, Hill RP. Hypoxia induces DNA overreplication and enhances metastatic potential of murine tumor cells. Proc Natl Acad Sci U S A 1988;85:9533-7

5 Coquelle A, Toledo F, Stern S, et al. A new role for hypoxia in tumor progression: induction of fragile site triggering genomic rearrangements and formation of complex DMs and HSRs. Mol Cell 1998;2:259-65.

6 Reynolds TY, Rockwell S, Glazer PM. Genetic instability induced by the tumor microenvironment. Cancer Res 1996:56:5754-7.

7 Saikumar P, Dong Z, Patel Y, et al. Role of hypoxia-induced Bax translocation and cytochrome $\mathrm{c}$ release in reoxygenation injury. Oncogene 1998;17:3401-15.

8 Aragones J, Jones DR, Martin S, et al. Evidence for the involvement of diacylglycerol kinase in the activation of hypoxia-inducible transcription factor-1 by low oxygen tension. J Biol Chem 2001;276:10548-55.

9 Santore MT, McClintock DS, Lee VY, et al. Anoxia-induced apoptosis occurs through a mitochondria-dependent pathway in lung epithelial cells. Am J Physiol Lung Cell Mol Physiol 2002;282:L727-34.

10 Harris AL. Hypoxia-a key regulatory factor in tumour growth. Nat Rev Cancer 2002;2:38-47

11 Hickman JA, Potten CS, Merritt AJ, et al. Apoptosis and cancer chemotherapy. Philos Trans R Soc Lond B Biol Sci 1994:345:319-25.

12 Carmeliet P, Dor Y, Herbert JM, et al. Role of HIF-1 alpha or in hypoxiamediated apoptosis, cell proliferation and tumour angiogenesis. Nature 1998;394:485-90.

13 Moritz W, Meier F, Stroka DM, et al. Apoptosis in hypoxic human pancreatic islets correlates with HIF- lalpha expression. FASEB J 2002; 16:745-7.

14 Akakura N, Kobayashi M, Horiuchi I, et al. Constitutive expression of hypoxia-inducible factor-1 alpha renders pancreatic cancer cells resistant to apoptosis induced by hypoxia and nutrient deprivation. Cancer Res 2001;61:6548-54.

15 Kotch LE, lyer NV, Laughner E, et al. Defective vascularization of HIF-1 alphanull embryos is not associated with VEGF deficiency but with mesenchymal cell death. Dev Biol 1999;209:254-67.

16 lyer NV, Kotch LE, Agani F, et al. Cellular and developmental control of O-2 homeostasis by hypoxia-inducible factor 1 alpha. Genes Dev 1998; 12:149-62.

17 Ryan HE, Lo J, Johnson RS. HIF-1 alpha is required for solid tumor formation and embryonic vascularization. EMBO J 1998;17:3005-15.

18 Zhong H, Agani F, Baccala AA, et al. Increased expression of hypoxia inducible factor- 1 alpha in rat and human prostate cancer. Cancer Res 1998;58:5280-4

19 Jiang BH, Agani F, Passaniti A, et al. V-SRC induces expression of hypoxiainducible factor 1 (HIF-1) and transcription of genes encoding vascular endothelial growth factor and enolase 1: involvement of HIF-1 in tumor progression. Cancer Res 1997; 57:5328-35.

20 Halterman MW, Miller CC, Federoff HJ. Hypoxia-inducible factor-1 alpha mediates hypoxia-induced delayed neuronal death that involves p53. J Neurosci 1999;19:6818-24.

21 Wang GL, Semenza GL. Purification and characterization of hypoxiainducible factor-1. J Biol Chem 1995;270:1230-7.

22 Salceda S, Beck I, Caro J. Absolute requirement of aryl hydrocarbon receptor nuclear translocator protein for gene activation by hypoxia. Arch Biochem Biophys 1996:334:389-94.
23 Semenza GL. Signal transduction to hypoxia-inducible factor 1. Biochem Pharmacol 2002;64:993-8.

24 Krieg M, Haas R, Brauch $H$, et al. Up-regulation of hypoxia-inducible factors HIF-lalpha and HIF-2alpha under normoxic conditions in renal carcinoma cells by von Hippel-Lindau tumor suppressor gene loss of function. Oncogene 2000; 19:5435-43

25 Epstein ACR, Gleadle JM, McNeill LA, et al. C-elegans EGL-9 and mammalian homologs define a family of dioxygenases that regulate HIF by prolyl hydroxylation. Cell 2001;107:43-54.

26 Jaakkola P, Mole DR, Tian YM, et al. Targeting of HIF-alpha to the von Hippel-Lindau ubiquitylation complex by O-2-regulated prolyl hydroxylation. Science $2001 ; 292: 468-72$.

27 Bruick RK, McKnight SL. A conserved family of prolyl-4-hydroxylases that modify HIF. Science 2001;294:1337-40.

28 Ravi R, Mookerjee B, Bhujwalla ZM, et al. Regulation of tumor angiogenesis by $\mathrm{p} 53$-induced degradation of hypoxia-inducible factor lalpha. Genes Dev 2000;14:34-44.

29 Bae MK, Ahn MY, Jeong JW, et al. Jabl interacts directly with HIF-l alpha and regulates its stability. J Biol Chem 2002;277:9-12.

30 Miller DL, Dibbens JA, Damert A, et al. The vascular endothelial growth factor mRNA contains an internal ribosome entry site. FEBS Lett 1998;434:417-20.

31 Lang KJ, Kappel A, Goodall GJ. Hypoxia-inducible factor-1 alpha mRNA contains an internal ribosome entry site that allows efficient translation during normoxia and hypoxia. Mol Biol Cell 2002;13:1792-801

32 Kvietikova I, Wenger $\mathrm{RH}$, Marti HH, et al. The transcription factors Aff- 1 and Creb-1 bind constitutively to the hypoxia-inducible factor-I (Hif-1) DNA recognition site. Nucleic Acids Res 1995;23:4542-50.

33 Semenza G. Signal transduction to hypoxia-inducible factor 1. Biochem Pharmacol 2002;64:993-8.

34 Schepop HAM, de Jong JS, van Diest PJ, et al. Counting of apoptotic cells: a methodological study in invasive breast cancer. Mol Pathol 1996:49:M214-17.

35 McClintock DS, Santore MT, Lee VY, et al. Bcl-2 family members and functional electron transport chain regulate oxygen deprivation-induced cell death. Mol Cell Biol 2002;22:94-104.

36 Gross A, Yin XM, Wang K, et al. Caspase cleaved BID targets mitochondria and is required for cytochrome $c$ release, while $B C L-X L$ prevents this release but not tumor necrosis factor-R1/Fas death. J Biol Chem 1999;274:1156-63.

37 Wei MC, Zong WX, Cheng EH, et al. Proapoptotic BAX and BAK: a requisite gateway to mitochondrial dysfunction and death. Science $2001 ; 292: 727-30$.

38 Li P, Nijhawan D, Budihardjo I, et al. Cytochrome $c$ and dATP-dependent formation of Apaf-1/caspase-9 complex initiates an apoptotic protease cascade. Cell 1997;91:479-89.

39 Nicholson DW, Thornberry NA. Caspases: killer proteases. Trends Biochem Sci 1997;22:299-306.

40 Nagata S, Golstein P. The Fas death factor. Science 1995;267:1449-56.

41 Fulda S, Meyer E, Debatin KM. Metabolic inhibitors sensitize for CD95 (APO$1 /$ Fas)-induced apoptosis by down-regulating Fas-associated death domainlike interleukin 1-converting enzyme inhibitory protein expression. Cancer Res 2000;60:3947-56

42 Morishima N, Nakanishi K, Takenouchi H, et al. An endoplasmic reticulum stress-specific caspase cascade in apoptosis. Cytochrome c-independent activation of caspase-9 by caspase-12. J Biol Chem 2002;277:34287-94.

$43 \mathrm{Kim}$ JY, Park JH. ROS-dependent caspase-9 activation in hypoxic cell death. FEBS Lett 2003;549:94-8

44 Basu S, Kolesnick R. Stress signals for apoptosis: ceramide and c-Jun kinase. Oncogene 1998:17:3277-85.

45 Kunz M, Ibrahim S, Koczan D, et al. Activation of c-Jun NH2-terminal kinase/ stress-activated protein kinase (JNK/SAPK) is critical for hypoxia-induced apoptosis of human malignant melanoma. Cell Growth Differ 2001;12:137-45.

46 Dong Z, Wang JZ, Yu F, et al. Apoptosis-resistance of hypoxic cells: multiple factors involved and a role for IAP-2. Am J Pathol 2003;163:663-71.

47 Dong Z, Nishiyama J, Yi XL, et al. Gene promoter of apoptosis inhibitory protein IAP2: identification of enhancer elements and activation by severe hypoxia. Biochem J, 2002;364:413-21.

48 Holcik M, Lefebvre $C$, Yeh CL, et al. A new internal-ribosome-entry-site motif potentiates XIAP-mediated cytoprotection. Nat Cell Biol 1999;1:190-2.

49 Devarajan P, De Leon M, Talasazan F, et al. The von Hippel-Lindau gene product inhibits renal cell apoptosis via $\mathrm{Bcl}$-2-dependent pathways. J Biol Chem $2001 ; 276: 40599-605$.

50 Alvarez-Tejado M, Naranjo-Suarez S, Jimenez C, et al. Hypoxia induces the activation of the phosphatidylinositol 3-kinase/Akt cell survival pathway in PC1 2 cells - protective role in apoptosis. J Biol Chem 2001 276:22368-74.

51 Bacus SS, Altomare DA, Lyass L, et al. AKT2 is frequently upregulated in HER$2 /$ neu-positive breast cancers and may contribute to tumor aggressiveness by enhancing cell survival. Oncogene 2002;21:3532-40.

52 Brusselmans K, Bono F, Maxwell $\mathrm{P}$, et al. Hypoxia-inducible factor-2 alpha (HIF-2 alpha) is involved in the apoptotic response to hypoglycemia but not to hypoxia. J Biol Chem 2001;276:39192-6.

53 Chen D, Li M, Luo J, et al. Direct interactions between HIF-1 alpha and Mdm2 modulate p53 function. J Biol Chem 2003;278:13595-8.

54 Hansson LO, Friedler A, Freund S, et al. Two sequence motifs from HIF- 1 alpha bind to the DNA-binding site of p53. Proc Natl Acad Sci U S A, 2002;99:10305-9.

55 An WG, Kanekal M, Simon MC, et al. Stabilization of wild-type p53 by hypoxia-inducible factor 1 alpha. Nature 1998;392:405-8.

56 Sowter HM, Ratcliffe PJ, Watson P, et al. HIF-1-dependent regulation of hypoxic induction of the cell death factors BNIP3 and NIX in human tumors. Cancer Res 2001;61:6669-73. 
57 Boyd JM. Adenovirus E1B $19 \mathrm{kDa}$ and Bcl-2 proteins interact with a common set of cellular proteins. Cell 1994;79:1121.

58 Bruick RK. Expression of the gene encoding the proapoptotic Nip3 protein is induced by hypoxia. Proc Natl Acad Sci U S A, 2000;97:9082-7.

59 Kothari S, Cizeau J, McMillan-Ward E, et al. BNIP3 plays a role in hypoxic cell death in human epithelial cells that is inhibited by growth factors EGF and IGF. Oncogene 2003;22:4734-44.

60 Vande Velde C, Cizeau J, Dubik D, et al. BNIP3 and genetic control of necrosis-like cell death through the mitochondrial permeability transition pore. Mol Cell Biol 2000;20:5454-68.

61 Chen J, Zhao SJ, Nakada K, et al. Dominant-negative hypoxia-inducible factor- 1 alpha reduces tumorigenicity of pancreatic cancer cells through the suppression of glucose metabolism. Am J Pathol 2003;162:1283-91.

62 Piret JP, Mottet D, Raes M, et al. Is HIF-l alpha a pro- or an anti-apoptotic protein? Biochem Pharmacol 2002;64:889-92.

63 Graeber TG, Osmanian C, Jacks T, et al. Hypoxia-mediated selection of cells with diminished apoptotic potential in solid tumours. Nature 1996;379:88-91.

64 Tsang RW, Fyles AW, Milosevic M, et al. Interrelationship of proliferation and hypoxia in carcinoma of the cervix. Int J Radiat Oncol Biol Phys 2000;46:95-9.

65 Kennedy AS, Raleigh JA, Perez GM, et al. Proliferation and hypoxia in human squamous cell carcinoma of the cervix: first report of combined immunohistochemical assays. Int J Radiat Oncol Biol Phys 1997;37:897-905.

66 Webster L, Hodgkiss RJ, Wilson GD. Simultaneous triple staining for hypoxia, proliferation, and DNA content in murine tumours. Cytometry 1995;21:344-51.

67 Raleigh JA, Zeman EM, Calkins DP, et al. Distribution of hypoxia and proliferation associated markers in spontaneous canine tumors. Acta Oncol 1995;34:345-9.

68 Nordsmark M, Hoyer M, Keller J, et al. The relationship between tumor oxygenation and cell proliferation in human soft tissue sarcomas. Int J Radiat Oncol Biol Phys 1996;35:701-8.

69 Bussink J, Kaanders JH, van der Kogel AJ. Tumor hypoxia at the microregional level: clinical relevance and predictive value of exogenous and endogenous hypoxic cell markers. Radiother Oncol 2003;67:3-15.

70 Levine EL, Renehan A, Gossiel R, et al. Apoptosis, intrinsic radiosensitivity and prediction of radiotherapy response in cervical carcinoma. Radiother Oncol 1995;37:1-9.
71 Tsang RW, Wong CS, Fyles AW, et al. Tumour proliferation and apoptosis in human uterine cervix carcinoma II: correlations with clinical outcome. Radiother Oncol 1999;50:93-101.

72 Sheridan MT, Cooper RA, West CM. A high ratio of apoptosis to proliferation correlates with improved survival after radiotherapy for cervical adenocarcinoma. Int J Radiat Oncol Biol Phys 1999:44:507-12.

73 Wheeler JA, Stephens LC, Tornos C, et al. ASTRO research fellowship: apoptosis as a predictor of tumor response to radiation in stage IB cervical carcinoma. American Society for Therapeutic Radiology and Oncology. Int J Radiat Oncol Biol Phys 1995;32:1487-93.

74 Zhong H, De Marzo AM, Laughner E, et al. Overexpression of hypoxiainducible factor lalpha in common human cancers and their metastases. Cancer Res 1999;59:5830-5.

75 Bos R, Zhong H, Hanrahan CF, et al. Levels of hypoxia-inducible factor- 1 alpha during breast carcinogenesis. J Natl Cancer Inst 2001:93:309-14.

76 Bos R, Van Der Groep, Greijer AE, et al. Levels of hypoxia-inducible factorlalpha independently predict prognosis in patients with lymph node negative breast carcinoma. Cancer 2003;97:1573-81.

77 Costa A Coradini D, Carrassi A, et al. Re: Levels of hypoxia-inducible factorlalpha during breast carcinogenesis. J Natl Cancer Inst 2001;93:1175-7.

78 Bos R, Van Diest PJ, Van Der Wall E. Response: levels of hypoxia-inducible factor-1 a during breast carcinogenesis. J Natl Cancer Inst 2001;93:1177.

79 Volm M, Koomagi R. Hypoxia-inducible factor (HIF-1) and its relationship to apoptosis and proliferation in lung cancer. Anticancer Res 2000;20:1527-33.

80 Volm M, Koomagi R. Hypoxia-inducible factor (HIF-1) and its relationship to apoptosis and proliferation in lung cancer. Anticancer Res 2000;20:1527-33

81 Giatromanolaki A, Koukourakis MI, Sivridis E, et al. Relation of hypoxia inducible factor 1 alpha and 2 alpha in operable non-small cell lung cancer to angiogenic/molecular profile of tumours and survival. $\mathrm{Br} J$ Cancer 2001;85:881-90

82 Koukourakis MI, Giatromanolaki A, O'Byrne KJ, et al. Potential role of bcl-2 as a suppressor of tumour angiogenesis in non-small-cell lung cancer. Int J Cancer 1997;74:565-70.

83 Unruh A, Ressel A, Mohamed HG, et al. The hypoxia-inducible factor-1 alpha is a negative factor for tumor therapy. Oncogene 2003;22:3213-20.

84 Aebersold DM, Burri P, Beer KT, et al. Expression of hypoxia-inducible factorlalpha: a novel predictive and prognostic parameter in the radiotherapy of oropharyngeal cancer. Cancer Res 2001;61:2911-16. 